\title{
- sin título -
}

\author{
Pablo Venegas Romero \\ Universidad de Valparaíso \\ pablo.venegas@uv.cl \\ Textos bajo licencia Creative Commons

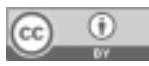 \\ Atribución 4.0 Internacional (CC BY 4.0)
}

Debo ser sincero y decir que escribir hoy me es más complejo que ayer, entendiendo por ayer todo tiempo pasado y hoy, el instante histórico en el que nos encontramos. Si bien la primera vez tuve la oportunidad de hacer una fotografía de la imagen textual de Panambí, hoy en cuarentena, la emocionalidad social da menos tregua para aquello; la cámara trepida frente a lo que acontece. De otra forma, podríamos decir que es mera casualidad o propio de cada momento editorial encontrarnos en cierta convulsión, como si apretásemos el modo turbo con cierta cadencia. Lo menciono con un simplismo arrogante, porque la situación humana ${ }^{1}$ actual excede lo que podría ser una agitación económica, política, social o religiosa; cada una, todas ellas y otras, como una crisis social de proporciones que se ha tomado la vida en contraparte. Independiente incluso del origen del problema, la situación COVID² nos tiene en circunstancias de límite dignas de un best seller, cual historia de ciencia ficción o de conspiraciones, sin negar ninguna de las anteriores. Digo también convulsión constante, pensando en que los periodos de agitación comienzan a ser recurrentes; en caso de muchos, ciertamente diarios. Otro ejemplo que a todos nos toca, tal la voluntad de resistir al embiste de la pandemia actual, es el cambio climático que sin duda deberemos enfrentar con firmeza y dedicación más pronto que tarde, algo que de importante pasó a ser urgente.

En este periodo confinado, octubre además será un mes significativo y trascendental, local y no recurrente, más bien histórico, como resultado de la movilización ciudadana que condujo a este plebiscito constitucional y que, si me lo permiten, debemos tomar como un compromiso para conducir a un mejor diálogo social y a la definición de dignidad. Votar, sin duda una responsabilidad, es asimismo una oportunidad para participar de una instancia irrepetible, donde la circunstancia COVID sumará una particularidad al análisis final; muchos son los factores que afectan y nos tienen afectados. Ya se cumplirá un año desde que la expresión social solicitara ahora fuertemente el derecho a construir y mirar nuestro futuro con todos incluidos, en paridad, considerando a los pueblos originarios, con espacio para abordar temas tan relevantes como el agua, o de poder enfrentar una crisis tan político-social como constitucional; si hacemos una foto del momento, como dijimos en nuestra primera editorial, el punctum se vuelve más importante que el studium.

En este alud de circunstancias, Panambí se publica con una mirada siempre centrada en la persona y ello dignifica al arte, que finalmente es en mi opinión la dimensión que agrega a la investigación una propiedad siempre cualitativa. En primera instancia y tal como lo resumen Invernizzi y Lozano, su manuscrito constituye un aporte a la construcción de un mapa de la geografía audiovisual sexodisidente durante los últimos 30 años en el documental latinoamericano, como una forma de reflexionar sobre la dignidad humana que ha sido expuesta de manera torcida por décadas. A continuación, la reflexión sobre la definición del concepto de producción en las artes escénicas, es abordado por Algán y Berstein, con una mirada integral sobre la acción de esta labor audiovisual. Del mismo modo, Saavedra analiza, con una aproximación a lo que denomina como una dramaturgia performativa, el texto de Crave, una obra de Sarah Kane, que en los noventa renovó la escena teatral en Inglaterra. Por su parte, León construye un modo tras y para el acto de dibujar, procurando abordar la figura humana en función de poder comprenderla y entonces representarla. Finalmente Oubiña, explora las tensiones que provocaron el que Cahiers du cinéma, una figura del ámbito editorial de la época, abandonara prácti-

1 Me refiero con toda su magnitud a la magnitud del concepto humano; en términos históricos, sociales y planetarios.

2 Por solo denominarlo así, entendemos creo la referencia sobre el CoronaVirus COVID19. 
camente la crítica cinematográfica para convertirse al activismo político propio del debate de los años setenta.

La investigación artística pone nuevamente en el centro del acta el factor humano, recordándonos como manifestase Gombrich, la idea del artista antes que el arte, a manera de una analogía de lo circunstancialmente actual; es en este sentido la contradicción al momento de escribir estas letras, que deben saber articular la presentación de los textos y la discusión sobre el conocimiento acá expresado, pero se soportan en un momento donde la reflexión no puede desligarse de lo que sucede y carga una sensación de vértigo que trasciende todas las esferas sociales y así nuestras actividades. Si bien todos son temas que cada autor ha venido trabajando con antelación, es importante resaltar, que al momento de la publicación, muchos, por no decir todos, hemos debido adaptar nuestras circunstancias para contrastar la incertidumbre; del mismo modo, artistas, investigadores, académicos, científicos, estudiantes y profesores han convertido sus casas en laboratorios y salas de clase para mantener en movimiento la actividad ${ }^{3}$, centrando la acción en las personas, como si de investigaciones artísticas se tratase, y con el propósito de evitar agrandar una crisis que marcará con un matiz saturado el 2020 en nuestra historia.

Cuando más que antes encontramos en entredichos la valorización de la investigación artística sostenida en la rentabilidad del indicador, en determinar el impacto como resultado de la mención, como una labor que debe ver resultados más desde el aspecto cuantitativo que cualitativo, la ciencia aparece en apoyo a la búsqueda de las certezas sociales y de salud que necesitamos, mientras el arte desde una de sus dimensiones se hace cargo de visibilizar la relevancia de la persona como eje de toda acción, más allá de los índices y no sólo en instancias de carácter investigativo como vemos acá, también siendo reflejo de la voz de la ciudadanía -en las calles, a través de los medios, en las escuelas y universidades-, de las personas y de una comunidad que este año verá en octubre la posibilidad de construir un diálogo social en conjunto, basado en condiciones de dignidad humana mínimas, que permitan el desarrollo de una sociedad más justa con un espacio para todos y cada uno.
Finalmente y con gran presencia en este número, Luis Escalona, dibujante porteño de excepción, que expone en nuestro inciso, acepta además la invitación a desarrollar su obra en Panambí; a trabajar in situ, el formato, el contexto, la comunicabilidad, a que su trabajo fuese parte de la revista y no solamente exhibido, en colaboración o como experiencia concebida durante el proceso editorial y enfrentado al plano de la revista, en conjunto con el contenido. Luis se sitúa acá entonces, en una dimensión de exploración, encontrando en la técnica del collage un espacio del arte para experimentar, desafiando al contexto definido, al espacio delimitado, pero también a su expresión y métodos. Vemos así cómo la portada y algunas portadillas ${ }^{4}$ que separan los artículos, se convierten en obras en sí mismas, desvirtuando su condición de espacio de exhibición para ser y hacer acción en el plano, tal el actor en escena cuando se apodera del escenario para hacerlo propio.

Esta obra - sin duda más profunda de lo que las palabras expresan-manifiesta una audacia que mantiene la sutileza de sus dibujos mientras el collage le permite traicionar esos límites, de la similitud, del tono académico, de la representación casi instantánea del gesto, para entrar ahora a un juego de composición donde construye una nueva obra, como obra de sus obras, ya despojadas de todo el rigor de esa incansable búsqueda por la delicadeza del trazo y del matiz, como de la luz y la sombra; ahora más bien, con una técnica que se articula casi a modo de una acción computacional provista del ensayo-error, o del comando 'CTRL+Z' que permite retroceder y modificar la decisión. La obra podrá fijarse y así constituirse como tal, o definirse como efímera si es que finalmente se hace evidente sólo a través de la fotografía que registra el momento de su lucidez, rompiendo el paisaje de la página de exposición para constituirse como obra in página en Panambí, asimismo un acercamiento a la investigación desde un arte editorial.
Pablo Venegas Romero

\section{Editor}

